atrial ablation purposes. ${ }^{3}$ However, it is a known fact that patients with long-standing AF, giant atria, or both have a much smaller chance to revert back to sinus rhythm after these ablation procedures. $^{4}$

Our findings, herein reported, might provide an explanation to understand this fact. As we have described, the morphologic consequences of chronic AF on the normal SN can be synthesized in 3 main features: (1) progressive tissue fibrosis, (2) progressive myocardial cell loss (including P cells), and (3) myocardial cell degeneration (including $\mathrm{P}$ cells). These SN morphologic abnormalities must inevitably lead to an impairment of its function. Thus normal sinus rhythm is less likely to be restored in patients with long-standing $\mathrm{AF}$, regardless of the atrial lesion pattern used to interrupt re-entry or the energy source used to create these lesions because their $\mathrm{SN}$ is morphologically and functionally abnormal. Conversely, surgical treatment of AF during its early stages, with minimal SN damage, is more likely to be successful.

\section{References}

1. James TA. The sinus node. Am J Cardiol. 1977;40:967-86.

2. Davies MJ, Pomerance A. Pathology of atrial fibrillation in man. $\mathrm{Br}$ Heart J. 1972;34:520-5.

3. Khargi K, Hutten BA, Lemke B, Deneke T. Surgical treatment of atrial fibrillation; a systematic review. Eur J Cardiothorac Surg. 2005;27: 258-65.

4. Chen MC, Chang JP, Chang HW, Chen CJ, Yang CH, Chen YH, et al. Clinical determinants of sinus conversion by radiofrequency maze procedure for persistent atrial fibrillation in patients undergoing concomitant mitral valvular surgery. Am J Cardiol. 2005;96:1553-7.

\title{
Rapidly progressive coronary ostial stenosis after aortic valve replacement in relapsing polychondritis
}

\author{
R. Karthik Vaidyanathan, MS, ${ }^{a}$ Jagannath Raghavendrarao Byalal, DNB (CTS), ${ }^{\text {a }}$ \\ Thiagarajamurthy Sundaramoorthi, FRCS (CTS), ${ }^{a}$ N. Madhu Sankar, DNB (CTS), PhD, a Joy M. Thomas, DM (card), \\ N. Alagu Meenakshi, BS (PA), ${ }^{\text {b }}$ and Kotturathu Mammen Cherian, FRACS, ${ }^{a}$ Chennai, India
}

$\mathrm{R}$ elapsing polychondritis is a rare multisystem disease characterized by inflammation of cartilage and other proteoglycan-rich structures, such as the eye, ear, heart, and blood vessels. ${ }^{1}$ Cardiovascular manifestations of this disease are rare, but they are the second most common cause of death in these patients. ${ }^{2}$ We report a case of relapsing polychondritis in which the patient underwent aortic valve replacement and had acute myocardial infarction caused by coronary ostial stenosis 6 months after the operation.

\section{Clinical Summary}

A 26-year-old woman presented with New York Heart Association class III dyspnea of 6 months' duration. She denied any anginal symptoms. Two years earlier, she was given a diagnosis of relaps-

From the Departments of Cardiac Surgery ${ }^{\mathrm{a}}$ and Cardiology, ${ }^{\mathrm{b}}$ Frontier Lifeline, International Centre for Cardiovascular and Thoracic diseases, Chennai, India.

Received for publication Jan 13, 2006; accepted for publication Jan 24, 2006.

Address for reprints: R. Karthik Vaidyanathan, MS, International Centre for Cardiovascular and Thoracic diseases, R 30 C Ambattur Industrial Estate Rd, Mogappair, Chennai-600101, India (E-mail: rkvdoc@ rediffmail.com).

J Thorac Cardiovasc Surg 2006;131:1395-6

$0022-5223 / \$ 32.00$

Copyright $\odot 2006$ by The American Association for Thoracic Surgery doi:10.1016/j.jtcvs.2006.01.032 ing polychondritis that had manifested as inflammation of the ear and depression of the nasal bridge. She had taken $20 \mathrm{mg} / \mathrm{d}$ oral prednisolone for a year and discontinued treatment because of relief of symptoms. She had clinical features suggestive of severe aortic regurgitation. Transthoracic echocardiography confirmed the presence of severe aortic regurgitation. Ejection fraction was $61 \%$. Erythrocyte sedimentation rate was $23 \mathrm{~mm} / 45 \mathrm{~mm}$. In view of her symptoms and severity of regurgitation, we decided to replace her aortic valve. Coronary angiography was not done because of her age, lack of anginal symptoms, and lack of electrocardiographic changes. Through a median sternotomy, cardiopulmonary bypass was instituted with cannulas in the ascending aorta and right atrium. Transverse aortotomy was performed, and cardioplegia was administered through the coronary ostia. The ascending aorta was thickened, and both coronary ostia appeared smaller than normal. The aortic valve was excised and replaced with a 23-mm Omni Carbon valve. Postoperative recovery was uneventful, and she was discharged home on the seventh postoperative day. Histology of the aortic valve revealed evidence of acute on chronic inflammation. Her New York Heart Association functional status improved to class I. She had recurrent inflammation of auricular cartilage 2 months after surgical intervention, and in consultation with the rheumatologist, she was restarted on $20 \mathrm{mg} / \mathrm{d}$ oral prednisone. She remained asymptomatic for 6 months and presented one day with acute-onset chest pain. Electrocardiography revealed acute anterior and lateral wall myocardial infarction. Coronary angiography revealed $75 \%$ and $90 \%$ ostial stenosis of the right and left coronary arteries, respectively. Immediate coronary artery bypass grafting was planned, but she sustained a fatal cardiac arrest while awaiting surgical intervention. 


\section{Discussion}

Cardiovascular involvement occurs in one fourth of patients with relapsing polychondritis. ${ }^{3}$ Aortic regurgitation is the most common cardiovascular complication and is seen in $4 \%$ to $9 \%$ of patients. ${ }^{4}$ Surgical intervention is rarely necessary for patients with cardiac involvement. Twenty-three such cases have been reported in the literature thus far, and all patients required aortic valve replacement. ${ }^{2}$ Aortic valve replacement alone is associated with high rates of reoperation within the first few years. Lang-Ladzdunski and associates $^{2,3}$ have reported that within 4 years, $23.8 \%$ of those who underwent aortic valve replacement had periprosthetic leak or aneurysm. Most $(52.6 \%)$ of the patients died of a cardiovascular cause in the same period. Inflammation of the aorta and friability caused by the use of steroids are thought to be responsible for surgical failures. A Bentall procedure does not carry a higher surgical risk in these patients and is probably the better option. ${ }^{3}$

Our patient had myocardial infarction caused by progressive coronary ostial stenosis. This is a very rare manifestation, and only one case has been reported thus far. ${ }^{5}$ Disease progression in the absence of use of an immunosuppressant like cyclophosphamide and trauma caused by the use of ostial cardioplegia could have accelerated the inflammatory process, leading to critical stenosis within a short span of 6 months. It is therefore better to use retrograde cardioplegia rather than traumatize the coronary ostia, especially in those in whom the ostia are only mildly involved by the disease process. Although the coronary ostia can be visualized
\end{abstract}

on the table, a preoperative coronary angiogram is essential because it would provide an objective measure of coronary ostial involvement. Thus a concomitant coronary artery bypass graft can be planned well in advance rather than encounter surprises on the table and face a dilemma about whether to graft. If the coronary ostial stenosis is not significant, a Bentall procedure alone would suffice. However, the coronary ostia should not be traumatized during the operation. These patients require close and careful lifelong follow-up to detect the onset of critical coronary ostial stenosis at a stage at which intervention would be beneficial. In this group of patients, steroids and cyclophosphamide can be added postoperatively, although their efficacy in preventing progression or relapses is not universal. ${ }^{4}$

\section{References}

1. Trentham DE, Le CH. Relapsing polychondritis. Ann Intern Med. 1998; 129:114-22.

2. Lang-Lazdunski L, Hvass U, Paillole C, Pansard Y, Langlois. Cardiac valve replacement in relapsing polychondritis. A review. Heart Valve Dis. 1995;4:227-35.

3. Lang-Lazdunski L, Pansard Y, Hvass U. Aortic valve replacement in relapsing polychondritis. J Thorac Cardiovasc Surg. 1997;114:131-2.

4. Selim A-GA, Fulford LG, Mohiaddin RH, Sheppard MN. Active aortitis in relapsing polychondritis. J Clin Pathol. 2001;54:890-2.

5. Yung A, Charleson HA, Ullal R, Doube A. A case of relapsing polychondritis with coronary ostial stenosis and severe aortic incompetence. Semin Arthritis Rheum. 2000;30:144-6.

\title{
Rapidly expanding right coronary artery aneurysm
}

\author{
Paolo Pepino, MD, ${ }^{a}$ Piermario Oliviero, MD, ${ }^{\mathrm{a}}$ Luigi Di Tommaso, ${ }^{\mathrm{b}}$ and Paolo Stassano, MD, ${ }^{\mathrm{b}}$ Castel Volturno \\ and Naples, Italy
}

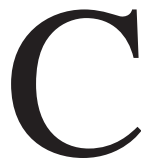

oronary artery aneurysm (CAA) is rare, its etiology is atherosclerotic in the majority of cases, and the right coronary artery (RCA) is the site of predilection. Usually its size remains constant or it enlarges slowly. ${ }^{1}$ Therefore, the presence of a CAA is not always considered to be a surgical indication. ${ }^{2,3}$ Anticoagulation and/or antiaggregation are the recommended treatments.

Rapidly expanding right CAA is different; such an aneurysm may rupture with potentially lethal consequences.

\footnotetext{
From the Department of Cardiothoracic Surgery, Clinica Pineta Grande, Castel Volturno (CE), Italy, ${ }^{a}$ and the Department of Cardiac Surgery, University Federico II, Naples, Italy. ${ }^{\mathrm{b}}$

Received for publication Jan 22, 2006; accepted for publication Jan 30, 2006.

Address for reprints: Paolo Pepino, MD, Via Manzoni 78, 80123, Naples, Italy (E-mail: paolo.pepino@fastwebnet.it).

J Thorac Cardiovasc Surg 2006;131:1396-7

$0022-5223 / \$ 32.00$

Copyright $\odot 2006$ by The American Association for Thoracic Surgery doi:10.1016/j.jtcvs.2006.01.037
}

We describe the case of a successful repair of a rapidly expanding right CAA with prompt surgical correction.

\section{Clinical Summary}

A 50-year-old male patient was admitted to our hospital for coronary angiography in June 2003 . He was completely asymptomatic and he denied any history of inflammatory or connective tissue disease. The electrocardiogram showed an abnormal ST tract. Results of the stress test were negative, but he smoked 40 cigarettes per day, was dyslipidemic and hypertensive, and had a positive family history of ischemic heart disease. Coronary angiography revealed normal coronary arteries but with a slow flow of contrast medium in the coronary bed and an aneurysm (Figure $1, \mathrm{~A})$ of the RCA. The patient was prescribed warfarin (international normalized ratio of 2.5) and was dischared from the hospital.

In May 2004 the patient, still asymptomatic, had a repeat coronary angiogram. There was no coronary stenosis, the flow in the coronary bed was as slow as in the previous year, but the right CAA was significativelly enlarged (Figure 1, B). The rapidity of enlargement of the CAA prompted surgical intervention even in the absence of symptoms. 